Article

\title{
High-Precision Monitoring of Volume Change of Commercial Lithium-Ion Batteries by Using Strain Gauges
}

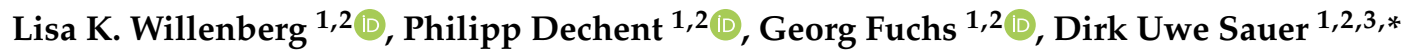 \\ and Egbert Figgemeier ${ }^{2,4, *}$ \\ 1 Institute for Power Electronics and Electrical Drives (ISEA), RWTH Aachen University, 52066 Aachen, \\ Germany; lisa.willenberg@isea.rwth-aachen.de (L.K.W.); Philipp.Dechent@isea.rwth-aachen.de (P.D.); \\ Georg.Fuchs@isea.rwth-aachen.de (G.F.) \\ 2 Juelich Aachen Research Alliance, JARA-Energy, 52062 Aachen, Germany \\ 3 Institute for Power Generation and Storage Systems (PGS), RWTH Aachen University, \\ 52062 Aachen, Germany \\ 4 Forschungszentrum Juelich GmbH, IEK-12, Helmholtz-Institut Münster, co ISEA of RWTH Aachen \\ University, 52066 Aachen, Germany \\ * Correspondence: batteries@isea.rwth-aachen.de (D.U.S.); egbert.figgemeier@isea.rwth-aachen.de (E.F.)
}

Received: 17 December 2019; Accepted: 9 January 2020; Published: 11 January 2020

\begin{abstract}
This paper proposes a testing method that allows the monitoring of the development of volume expansion of lithium-ion batteries. The overall goal is to demonstrate the impact of the volume expansion on battery ageing. The following findings are achieved: First, the characteristic curve shape of the diameter change depended on the state-of-charge and the load direction of the battery. The characteristic curve shape consisted of three areas. Second, the characteristic curve shape of the diameter change changed over ageing. Whereas the state-of-charge dependent geometric alterations were of a reversible nature. An irreversible effect over the lifetime of the cell was observed. Third, an s-shaped course of the diameter change indicated two different ageing effects that led to the diameter change variation. Both reversible and irreversible expansion increased with ageing. Fourth, a direct correlation between the diameter change and the capacity loss of this particular lithium-ion battery was observed. Fifth, computer tomography (CT) measurements showed deformation of the jelly roll and post-mortem analysis showed the formation of a covering layer and the increase in the thickness of the anode. Sixth, reproducibility and temperature stability of the strain gauges were shown. Overall, this paper provides the basis for a stable and reproducible method for volume expansion analysis applied and established by the investigation of a state-of-the-art lithium-ion battery cell. This enables the study of volume expansion and its impact on capacity and cell death.
\end{abstract}

Keywords: lithium-ion batteries; ageing; mechanical fatigue; volume change; measurement technique; silicon anode

\section{Introduction}

Mechanical characteristics of lithium-ion battery cells are of major importance when designing applications with maximized energy density and lifetime [1,2]. With the inherent volume variations during the use of lithium-ion batteries, the integration of cells into modules, packs, and systems needs to account for geometric variations and the induced mechanical stresses changing with state-of-charge and state-of-health [3,4]. In this context, an inappropriate design will lead to premature ageing of components on all levels. In extreme cases, a mismatch of volume requirements and device integration can lead to catastrophic failure [5]. 
In the past, chemical and electrochemical ageing effects of lithium-ion batteries have been the major focus in the international research community. Topics such as side reactions, the solid electrolyte interphase (SEI) growth, loss of lithium inventory, and separator clogging have been investigated in great detail [6-9]. The influence of mechanical ageing has often been ignored and is now attracting attention with the aim of the highest energy densities and the introduction of alloying materials with high volume variations during charging and discharging [3]. Moreover, complex system integration in electric vehicles requires detailed understanding and quantitative prediction of geometric variations as a function of state-of-charge and state-of-health.

Mechanical ageing might be one of the reasons for early and unexpected cell death, especially considering that graphite can expand up to $7-12 \%[3,10,11]$, Lithium Nickel Cobalt Aluminium Oxide (NCA) up to 5\% [3], Nickel Manganese Cobalt (NMC) 1-2\% [3,12,13], and silicon up to $280 \%$ [14] within the given voltage limits. Thus, the question to be clarified is how serious is the influence of mechanics on cell ageing in commercially relevant cells with respect to its used case?

The volume change can have various causes: The first is lithium migration, in which electrode materials change in volume as a result of lithium intercalation and deintercalation into their crystal structures [14-18]. In addition, the gas formation can occur due to side reactions $[6,19,20]$. Furthermore, it is known that thick layers of electrolyte decomposition products are formed as an almost impermeable covering layer $[6,21,22]$. Alternatively, lithium plating can also occur, resulting in swelling behavior $[6,23,24]$.

It has already been shown by other measurement methods, such as thickness gauge [3,25-27], pressure [3], digital image correlation, [28] and multi-scale investigation [11], that a volume change takes place, which is strongly material dependent and measures between 3 and $10 \%$ for a full cell $[3,11,25-28]$ between charge and discharge.

For our study, we investigated an ageing matrix consisting of 51 Samsung 35E battery cells. Twelve different ageing conditions were applied and a minimum of three batteries per ageing point were tested. At three ageing points, the C-rate was additionally varied with two batteries each. Before the data of all batteries can be evaluated in detail, the measuring method must be verified in a first step. Because long time frames of the study, in combination with expected effects in the lower micrometer range, it desires a careful evaluation of the method. In this context, the current study evaluates the application of strain gauges as a valuable tool to monitor geometric changes in cylindrical cells with high precision. Firstly, the validity of the strain gauge is evaluated by investigating the signal drifts as a function of temperature and time. Secondly, the results from one battery are presented as an illustrative example. Finally, a post-mortem investigation was performed. The data of the strain gauge, in combination with electrochemical characterization, gives information regarding the lithium-ion battery and their degradation as well as parameters for battery system designs.

\section{Materials and Methods}

\subsection{Investigated Lithium-Ion Battery}

A commercially available lithium-ion battery, Samsung SDI INR18650 35E, was selected as the test object to check the functionality of the strain gauge. Verification measurements and ageing measurements were carried out on this lithium-ion battery.

The battery's specifications are given in Table 1 . The investigated battery was a high-energy lithium-ion battery with a usable voltage range of $2.65-4.20 \mathrm{~V}$ according to the datasheet of the producer [29]. 
Table 1. Specification of the investigated lithium-ion battery [29].

\begin{tabular}{cc}
\hline & Samsung SDI INR18650 35E \\
\hline Diameter & Max. $\Phi 18.55 \mathrm{~mm}$ \\
Length w/o terminals & Max. $65.25 \mathrm{~mm}$ \\
Cell weight & $50.00 \mathrm{~g} \mathrm{max}$ \\
Standard discharge capacity & Min. $3350.00 \mathrm{mAh}$ \\
Charging voltage & $4.20 \mathrm{~V}$ \\
Discharge cut-off voltage & $2.65 \mathrm{~V}$ \\
Max. charge current & $2.00 \mathrm{~A}$ \\
Max. discharge current & $8.00 \mathrm{~A}$ (for continuous discharge) \\
Operating temperature & Charge: 0 to $45^{\circ} \mathrm{C}$ \\
(cell surface temperature) & Discharge: -10 to $60{ }^{\circ} \mathrm{C}$ \\
Initial internal impedance & Initial internal impedance measured at $\mathrm{AC} 1 \mathrm{kHz}$ after \\
& Standard charge. \\
& Initial internal impedance $\leq 35 \mathrm{~m} \Omega$ \\
\hline
\end{tabular}

Computer tomography (CT) measurements were performed in order to obtain more information about the geometry and construction details of the investigated battery cell. A Werth TomoScope HV Compact (Werth Messtechnik GmbH, Gießen, Germany) was used with a microfocus transmission tube with up to $225 \mathrm{kV}$. All shown images have a resolution of $38 \mu \mathrm{m} /$ voxel. The visualization software myVGL 3.2.5 (Volume Graphics GmbH, Heidelberg, Germany) was used for analyzing the data.

One Samsung 35E lithium-ion battery was opened under an argon atmosphere. A remaining voltage of $2.60 \mathrm{~V}$ was measured directly before opening. Spatially distributed discs of the double-coated electrodes, with a diameter of $20 \mathrm{~mm}$, were taken. As preparation, each sample was washed with Dimethylcarbonat (Dimethylcarbonat Msynth ${ }^{\circledR}$ plus, Merck KGaA, Darmstadt, Germany) before it was dissolved in aqua regia. The solution was filled with distilled water until a $100 \mathrm{ml}$ solution was obtained. Induced coupled plasma-optical emission spectrometer (ICP-OES) was conducted on this solution. The electrode compositions of anode and cathode were measured with Varian 725 induced coupled plasma-optical emission spectrometer (Agilent, Santa Clare, USA). The electrodes and the separator were evaluated by their surface morphology and color using a Keyence VK-9710 laser microscope (KEYENCE DEUTSCHLAND GmbH, Neu-Isenburg, Germany).

\section{Electrical Tests}

For examination and ageing of the lithium-ion battery, the cell test system Digatron MCFT 20-05-50ME with the precision of the current measurement of $0.2 \%$ (Digatron Power Electronics $\mathrm{GmbH}$, Aachen, Germany) was used. The temperature sensor Dallas Semiconductor DS18B20 (Maxim Integrated, San Jose, USA) with a precision of $\pm 1{ }^{\circ} \mathrm{C}$ was located on the lithium-ion battery case close to the strain gauge.

The lithium-ion battery test was conducted in a temperature chamber Binder MK 720 (BINDER $\mathrm{GmbH}$, Tuttlingen, Germany) with a temperature precision of $\pm 2{ }^{\circ} \mathrm{C}$. The experiment was conducted at a constant ambient temperature of $25^{\circ} \mathrm{C}$. However, the lithium-ion battery temperature may have changed due to self-heating depending on the current.

The battery was electrically aged by charge-discharge cycling. The ageing cycles were performed at $25^{\circ} \mathrm{C}$ and a mean state of charge (SOC) of $50 \%$. A cycle depth of $50 \%$ was chosen. The lithium-ion battery was charged with $0.5 \mathrm{C}$ to the upper charging voltage limit and discharged Ah-based to avoid voltage drift.

In order to determine the ageing of the lithium-ion battery, check-ups were performed at $25^{\circ} \mathrm{C}$. Check-ups were done every 50th equivalent full cycle and included capacity determination, pulse resistance, and quasi-open-circuit voltage (quasi-OCV) characteristics. During the check-up, the lithium-ion battery was first discharged down to $2.65 \mathrm{~V}$, followed by a pause of $10 \mathrm{~min}$. Then the battery was charged with $0.5 \mathrm{C}(1.7 \mathrm{~A})$ up to $4.20 \mathrm{~V}$, followed by constant-voltage charging up to 
I $<0.02 \mathrm{C}$ (maximum $180 \mathrm{~min}$ ). Afterwards, the lithium-ion battery was kept at rest for $30 \mathrm{~min}$ before the capacity was determined with a discharge of $0.5 \mathrm{C}$ until the voltage of $2.65 \mathrm{~V}$ was reached, followed by a pause of $10 \mathrm{~min}$. Next, the lithium-ion battery was charged, followed by a pause of $30 \mathrm{~min}$.

The quasi-OCV was measured with a current of 0.1C. For this, the lithium-ion battery was discharged down to $2.65 \mathrm{~V}$ and charged up to $4.20 \mathrm{~V}$ with a current of $0.1 \mathrm{C}$, followed by a pause of $30 \mathrm{~min}$.

\subsection{Strain Gauges}

The strain gauge 1-LY11-6/120A from HBM Germany (Hottinger Baldwin Messtechnik GmbH, Darmstadt, Germany) was attached to the lithium-ion battery housing with superglue Z70 (Hottinger Baldwin Messtechnik GmbH, Darmstadt, Germany) according to the enclosed manufacturer's instructions. It was assumed that the height (z-direction) of the battery does not change, as there is enough buffer in the housing in this direction. Therefore, it was assumed that only the diameter will change. In order to measure the change in diameter without the influence of edge effects, the strain gauge was placed in the middle of the housing height in the circumferential direction.

The area and the measuring grid area of the strain gauge were $6 \times 13 \mathrm{~mm}^{2}$ and $6 \times 2.7 \mathrm{~mm}^{2}$, respectively. The resistance of the strain gauge was the electrical resistance between the two connecting cables. The change in volume of the measuring body caused a strain of the measuring grid. Due to the strain of the measuring grid, the resistance of the measuring grid changed [30]. This resistance change induced a signal which was amplified by a measuring amplifier Q.bloxx A116 120/350 and converted into a strain $\varepsilon$ in $\mu \mathrm{m} / \mathrm{m}$ by Gantner Q.station 101DT (Gantner Instruments Test \& Measurement GmbH, Darmstadt, Germany) according to Equation (1).

$$
\varepsilon=\frac{\text { signal }}{k} \times \frac{4}{F} \times 1000
$$

The signal is the measured signal of the strain gauge. The $k$ factor is the characteristic value of a strain gauge. The value here is $k=2.04$. The bridge factor $F$ indicates how many active strain gauges are present in the Wheatstone bridge. For a quarter bridge, the manufacturer indicated a value of one.

The resulting diameter change of the cylindrical lithium-ion battery is calculated as follows: It is assumed that the elongation of the lithium-ion battery in the circumferential direction is constant over the height of the casing. The change in diameter can be inferred from the elongation of the circumference using Equation (2).

$$
\Delta d=\frac{U_{0}+U_{0} \times(\varepsilon-\varepsilon(1))}{\pi}-d_{0}
$$

$\Delta d$ is the diameter change of the lithium-ion battery. $U_{0}$ in mm represents the circumference at the start of the test. $U_{0}$ is calculated using Equation (3). $\varepsilon$ is the measured strain in $\mu \mathrm{m} / \mathrm{m}$ and $d_{0}$ is the diameter at the start of the test. In our case, this corresponds to $18.5 \mathrm{~mm}$.

$$
U_{0}=\pi \times d_{0}
$$

\section{Results}

\subsection{Analysis of Cylindrical Cell}

The Samsung 35E was analyzed by ICP-OES. The anode consists of graphite and a small fraction of silicon was detected. The cathode consists out of nickel-cobalt-aluminum with a high amount of nickel as the cathodic active material.

The construction of the Samsung 35E lithium-ion battery cell consists of a jelly roll with a mandrel in the centre, see Figure 1. The electrode is wound 19 times around the mandrel. The current tab of the anode is located at the outer edge of the jelly roll, see Figure 1a. The cathode current tab is placed in the 
middle of the jelly roll. The diameter of the entire lithium-ion battery is given as a maximum value of $18.55 \mathrm{~mm}$, according to the datasheet [29]. For the calculation using Equation (2), $18.5 \mathrm{~mm}$ was used.

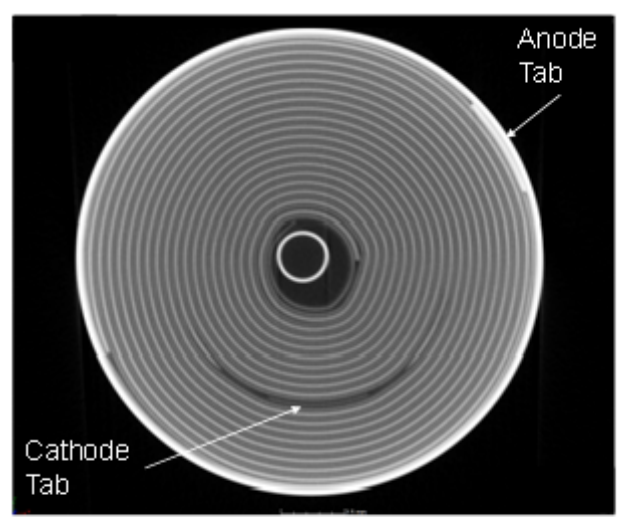

(a)

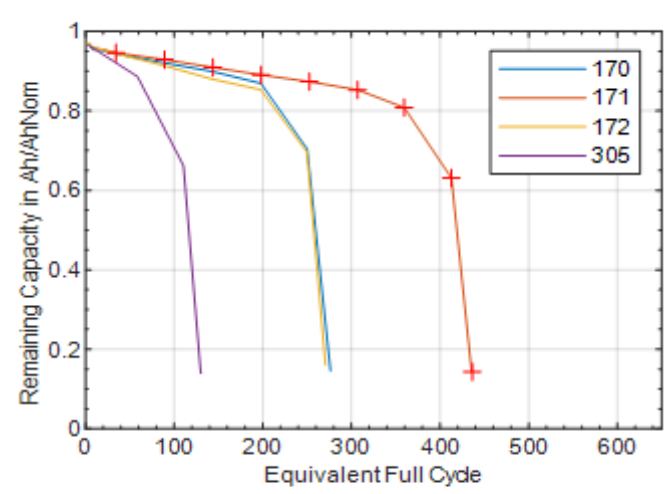

(b)

Figure 1. (a) Computer tomography (CT) measurement of an as-received Samsung 35E (347) with the location of the electrode tabs. (b) Remaining capacity over equivalent full-cycle measured during check-ups with a current of $0.5 \mathrm{C}$ of Samsung 35E $(170,171,172,305)$ of the electrical ageing at a mean state of charge (SOC) of $50 \%$ and a cycle depth of $50 \%$. Each cell was displayed in a different color. The red crosses mark the time of the check-ups.

Figure $1 \mathrm{~b}$ shows the remaining capacity of four lithium-ion batteries over equivalent full cycles. The cycle ageing was performed at a mean SOC of $50 \%$ and a cycle depth of $50 \%$ for all four battery cells. As can be seen, these lithium-ion battery cells aged linearly first at a rate of $0.5 \mathrm{C}$, which was above the recommended maximum C-rate in order to accelerate ageing effects. Afterwards, the remaining capacity dropped strongly. All four cells showed a fast cell death. The reason for the fast cell death may be the increased C-rate of $0.5 \mathrm{C}$. The manufacturer recommends $1 / 3 \mathrm{C}$. If this battery is aged with $1 / 3 C$, it reaches clearly higher cycle numbers of more than 1000 equivalent full cycles. Furthermore, rather large variations in ageing characteristics can be seen at this ageing point. This fits the rather large variations in ageing characteristics, which had been observed for this battery type in the entire ageing matrix. Since these results are not the focus of this paper, they will be described in another paper. In the following, only the battery Samsung 35E 171 will be discussed to focus on the topic of this publication.

\subsection{Validation of the Measurement Process}

The strain $\varepsilon$ was measured according to Equation (1) and is indicated in $\mu \mathrm{m}$. According to the manufacturer, the maximum extensibility of the sensor is $50,000 \mu \mathrm{m} / \mathrm{m}$ [30]. The maximum strain change in our measurement was $1000 \mu \mathrm{m} / \mathrm{m}$ per full cycle of a lithium-ion battery. The exact maximum diameter change depends on the preload of the strain gauge. With an alternating strain of $\varepsilon_{\mathrm{W}}= \pm 1000 \mu \mathrm{m} / \mathrm{m}$, a zero-point change of $\varepsilon_{\mathrm{m}} \Delta \leq 30 \mu \mathrm{m} / \mathrm{m}$ can be expected with more than $10^{7}$ load cycles [30]. With our measurements, we perform 100 load cycles per 50 equivalent full cycles (cycle depth of 50\%). This resulted in 100,000 equivalent full cycles until we exceed the limit of $10^{7}$ load cycles confirming the suitability of the strain gauge for the current task.

To investigate the volume change of the battery, its diameter change was calculated using Equation (2). Figure 2a shows the diameter change drift depending on the temperature at five different temperatures for more than $20 \mathrm{~h}$. The strain gauge was attached as described in chapter 2.2. As can be seen, the resulting diameter change was stable over the relevant time period. 


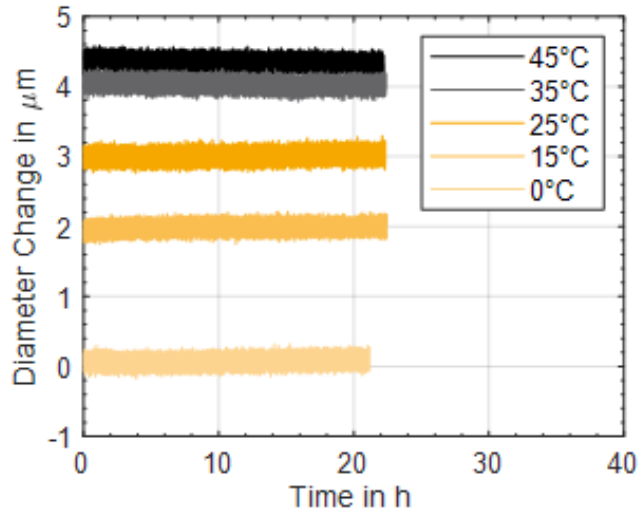

(a)

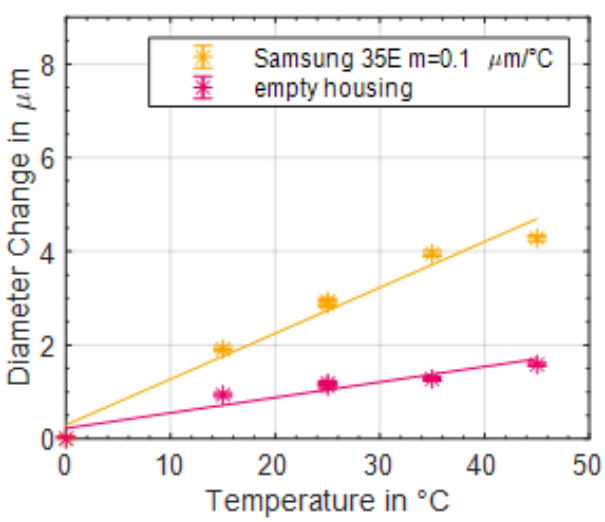

(b)

Figure 2. (a) Diameter change of a lithium-ion battery cell (197) at different temperatures. (b) Derivation of the temperature dependence of the Samsung 35E (197) and of an empty battery housing with a strain gauge including a standard deviation over the measured $20 \mathrm{~h}$.

Based on these results (Figure 2a), a relationship between diameter change of the lithium-ion battery together with the strain gauge and the temperature can be derived, see Figure $2 b$. The strain gauge and the Samsung 35E together are changing their diameter by $0.1 \mu \mathrm{m} /{ }^{\circ} \mathrm{C}$.

In order to determine the temperature influence of the jelly roll (including electrode stack and electrolyte), the diameter change of a battery housing without jelly roll was measured, see Figure $2 \mathrm{~b}$. The strain gauge and the empty battery housing together are changing their diameter below the limits of detection.

In order to investigate the temperature cycle stability of the strain gauge, a Samsung 35E lithium-ion battery and an empty housing with strain gauges were temperature cycled between 0 and $40{ }^{\circ} \mathrm{C}$. Figure 3 shows an extract of the measurement. In total, 15 temperature cycles were performed. Every ten hours, the temperature was changed in the climate chamber. Figure 3 shows two temperature cycles of 15 as an example.

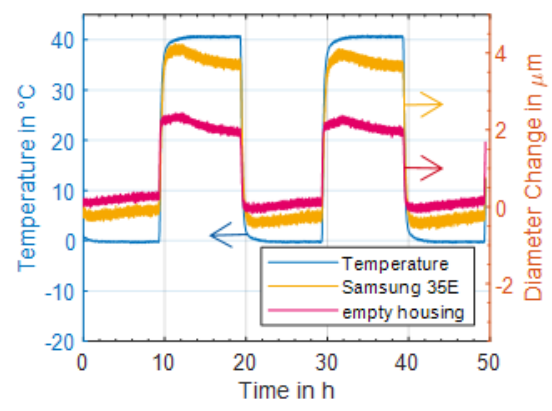

Figure 3. Measurement of the diameter change on a Samsung 35E (197) lithium-ion battery during temperature cycling between 0 and $40^{\circ} \mathrm{C}$. The temperature of the climate chamber was changed every $10 \mathrm{~h}$.

The temperature cycle stability is shown in Figure 4 based on the measurement shown in Figure 3. In Figure 4a the mean results and the standard deviation of $40{ }^{\circ} \mathrm{C}$ of the Samsung 35E and the empty housing are shown. The mean results and standard deviations were calculated from the results shown in Figure 3. At $40^{\circ} \mathrm{C}$, the mean diameter change of the empty housing was stable with a maximum standard deviation of $0.1 \mu \mathrm{m}$. The mean diameter change of the Samsung $35 \mathrm{E}$ was decreasing with the temperature cycle number with a maximum standard deviation of $0.33 \mu \mathrm{m}$. Figure $4 \mathrm{~b}$ shows the mean results and the standard deviation at $0{ }^{\circ} \mathrm{C}$. At $0{ }^{\circ} \mathrm{C}$, the same behavior can be observed. The maximum deviation of the Samsung 35E and the empty housing was $0.1 \mu \mathrm{m}$ and $0.1 \mu \mathrm{m}$, respectively. 


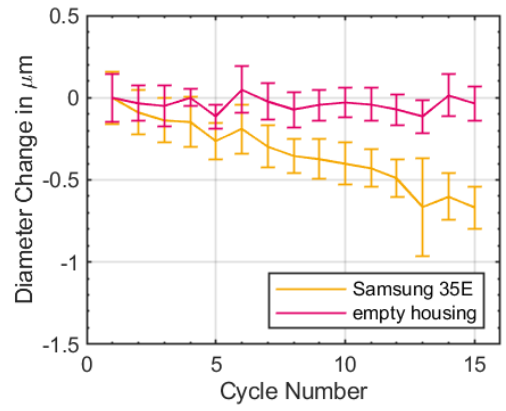

(a)

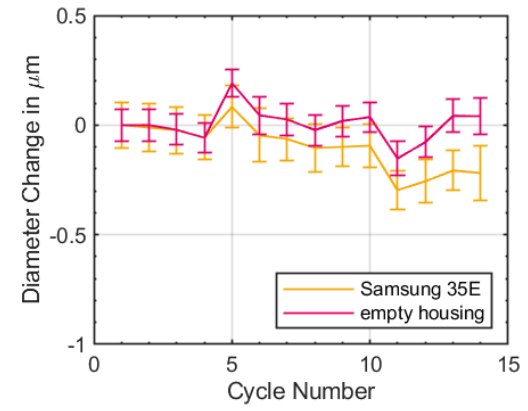

(b)

Figure 4. Measurement of the diameter change on a lithium-ion battery during temperature cycling between 0 and $40{ }^{\circ} \mathrm{C}$. The temperature of the climate chamber was changed every $10 \mathrm{~h}$. (a) shows the mean temperature and mean diameter change with standard deviation at $40^{\circ} \mathrm{C}$ of the lithium-ion battery Samsung 35E and an empty housing (average of the numbers between 35 and $40^{\circ} \mathrm{C}$ ) and (b) at $0{ }^{\circ} \mathrm{C}$ (average of the numbers between 0 and $5^{\circ} \mathrm{C}$ ).

\subsection{Diameter Change of Samsung 35E During Electrical Ageing}

Figure 5 shows the discharge voltage profile and the associated change in diameter over the state of discharge for a lithium-ion battery cell as-received.

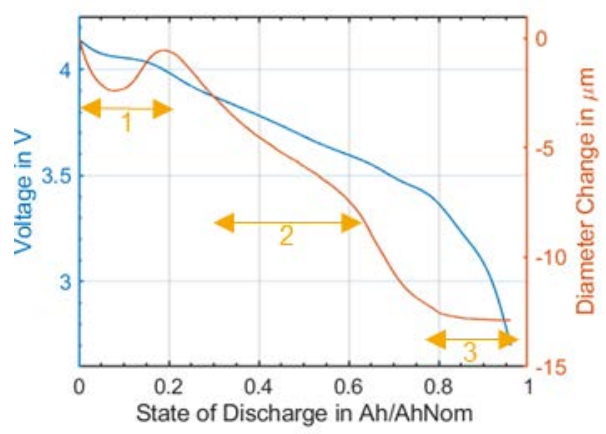

Figure 5. Diameter change and voltage profile from a $0.1 \mathrm{C}$ discharge between 4.2 and $2.65 \mathrm{~V}$ of an as-received lithium-ion battery at $25^{\circ} \mathrm{C}(171)$.

At the beginning of the discharge, the diameter change decreases until it reached a minimum of at approximately $10 \%$ state of discharge. Then, the volume rised again up to a maximum at $20 \%$ state of discharge in area 1 in Figure 5. The maximum was below the diameter at the beginning of the measurement. Afterwards, the diameter change decreased again. Between a state of discharge of $40 \%-60 \%$, the diameter change was flatter than before. An area with a constant gradient can be seen in area 2 . From $60 \%$ state of discharge onwards, the diameter change decreased again until it flattened out, starting from $75 \%$ onwards and remained constant until the lithium-ion battery was discharged in area 3.

Figure 5 shows a representative measurement. Overall, 51 specimens were tested. The experiments showed a diameter change of around $10.7 \mu \mathrm{m}$ with a standard deviation of $4.4 \mu \mathrm{m}$ for an as-received lithium-ion battery during a full discharge process.

For the comparison of charge and discharge, the discharged lithium-ion battery was normalized to SOC of $0 \%$. In a check-up, the battery was first discharged to $0 \%$ SOC and then charged to $100 \%$ SOC.

When comparing the diameter change of a charge and discharge of a lithium-ion battery, the shape differed, see Figure $6 \mathrm{a}$. When the lithium-ion battery was charged, its change in diameter increases directly from $0 \%$ onwards, see Figure $6 \mathrm{~b}$. When it is discharged, the range up to $10 \%$ SOC was rather flat. The area with a constant gradient between $40 \%$ and $60 \%$ SOC was more pronounced with the charge than in the discharge, see area 2. This is where the deviation was most noticeable. During 
discharge, the slope at 30\% SOC was greater than during charge. Furthermore, the turning point became less evident at $60 \%$ SOC. The charge and discharge curve cross each other at $30 \%$ and $70 \%$ SOC. Afterwards, both curves take the same course. The minimum at high SOCs is showing the same for both the charge and the discharge, see area 1.

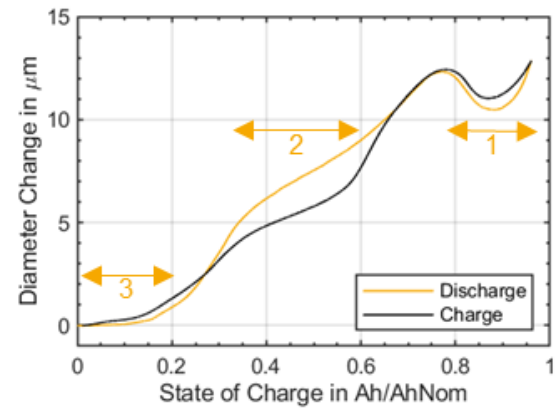

(a)

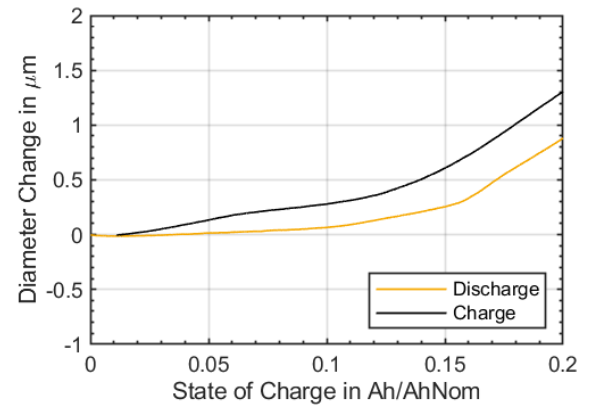

(b)

Figure 6. Diameter change of the Samsung 35E (171) during discharge and charge between 4.2 and $2.65 \mathrm{~V}$ at $0.1 \mathrm{C}$ and $25^{\circ} \mathrm{C}(\mathbf{a})$ between stage of charge $0-1 \mathrm{Ah} / \mathrm{Ah}_{\mathrm{Nom}}$ and (b) enlargement between stage of charge $0-0.2 \mathrm{Ah} / \mathrm{Ah}_{\mathrm{Nom}}$.

Figure 7 shows the diameter change due to ageing as a function of SOC and capacity (a) discharge and (b) charge. Each curve represents one check-up performed on the same lithium-ion battery. All curves were normalized to the diameter of the beginning of life check-up.

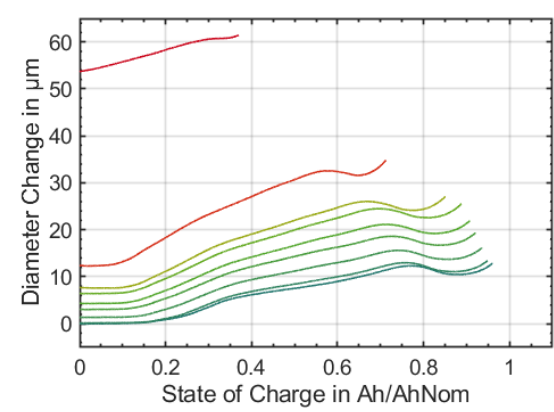

(a)

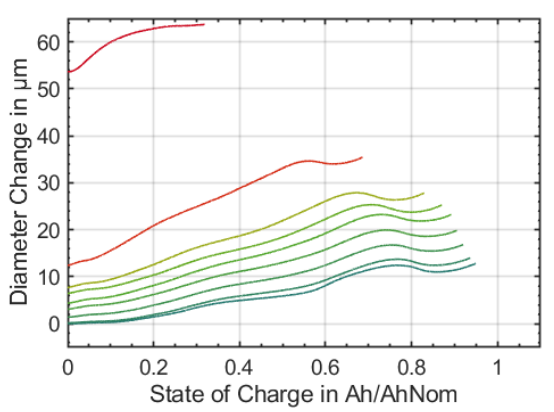

(b)

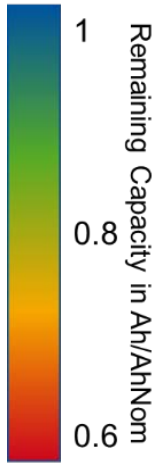

Figure 7. Diameter change measured with $0.1 \mathrm{C}$ over SOC at the check-ups for (a) discharge and (b) charge. The lithium-ion battery (171) was aged at a mean SOC of 50\% and a cycle depth of $50 \%$ with $0.5 \mathrm{C}$.

The shape of the curves remains nearly the same until a remaining capacity of $80 \%$. Then the diameter change shrinks and the areas 1 and 3 start to disappear. In addition, the distance between the curves increases. After the seventh check-up the lithium-ion battery suddenly suffered a rapid capacity loss, see Figure $1 b$. This was accompanied by a significant increase in diameter. In addition, the area with a constant gradient in area 2 is no longer clearly visible. There were no major differences between charging and discharging during ageing. Only the last check-up showed a clearly different curve. During discharge, the change in diameter increased linearly and the minimum was still recognizable at the end of the curve. During charge, the diameter change followed an s-shape curve.

Figure 8 shows the diameter change over ageing during discharge at "SOC 0\%", "SOC 100\%", and the "difference" between both. Two different volume change mechanism can be observed: First, a reversible diameter change caused by charging and discharging (lithiation and delithiation of the electrodes), represents here as the "difference" between diameter at "SOC $0 \%$ " and diameter at "SOC $100 \%$ ". The reversible diameter change "difference" increased with ageing until the end of life of 
the lithium-ion battery. Here, the diameter change difference was decreasing again. Secondly, an irreversible diameter change can be observed. It was clearly distinguishable with progressing ageing: The diameter change values at "SOC $0 \%$ " and "SOC $100 \%$ " change and induced a moving "difference" during ageing which is reversible. The irreversible diameter change, the basic level of the lithium-ion battery diameter rised with ageing, both "SOC $0 \%$ " and "SOC 100\%". At the end of life, the lithium-ion battery had a diameter change of above $60 \mu \mathrm{m}$ in the fully charged state (SOC 100\%).

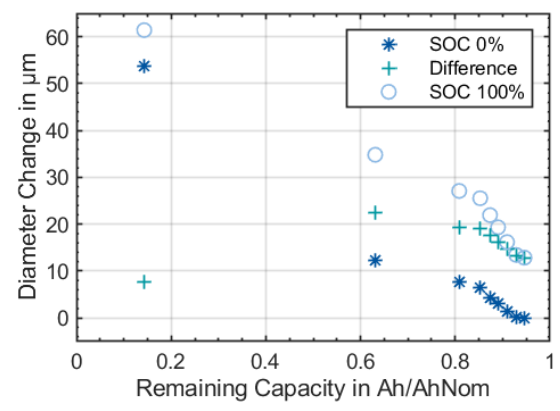

Figure 8. Diameter change measured with $0.1 \mathrm{C}$ over remaining capacity at SOC $0 \%$, SOC $100 \%$, and the difference for discharge. The lithium-ion battery (171) was aged at a mean SOC of $50 \%$ and a cycle depth of $50 \%$ with $0.5 \mathrm{C}$.

In addition, it was noticeable that the diameter change curves took an s-shaped course up to a remaining capacity of $80 \%$, see Figure 8 . Thereafter, the expansion increased linearly. The results of the charge behaved the same as the discharge.

Looking at the increase of the mean diameter change not during the check-ups but during the cyclisation, it can be seen that the mean diameter change increased slowly up to a cycle number of about 700 cycles, shown in Figure 9. Afterwards there was a steep increase in the mean diameter change. This process fits very well to the previously shown diameter changes during the check-ups, shown in Figures 7 and 8. There are small increases in the mean diameter change due to the check-ups.

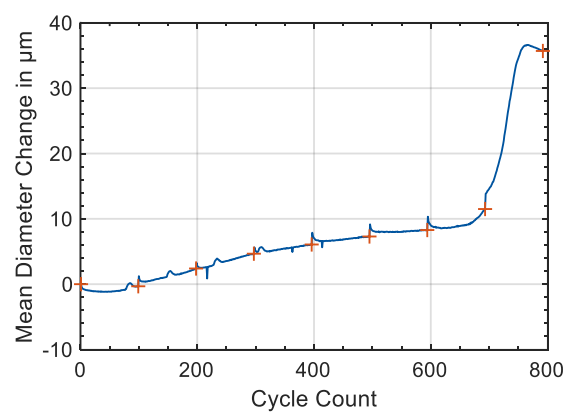

Figure 9. Mean diameter change of the Samsung 35E (171). For the diameter change curve, the mean diameter change from the ageing cycles (SOC of $50 \%$ and a cycle depth of $50 \%$ with $0.5 \mathrm{C}$ ) during charging was used. Therefore, this was applied over cycles and not equivalent full-cycles. The red crosses mark the time of the check-ups.

The temperature changes during quasi-OCV was less than $1{ }^{\circ} \mathrm{C}$. During an entire check-up, the temperature changed from $25^{\circ} \mathrm{C}$ to a maximum of $30^{\circ} \mathrm{C}$ during the capacity test. As can be seen inFigure 10, the outside mean temperature of the lithium-ion battery during each cycle rised constantly until a cycle count of 600 . Afterwards, the mean temperature increased faster until the end of life. However, $30^{\circ} \mathrm{C}$ was not exceeded during the entire aging process. 


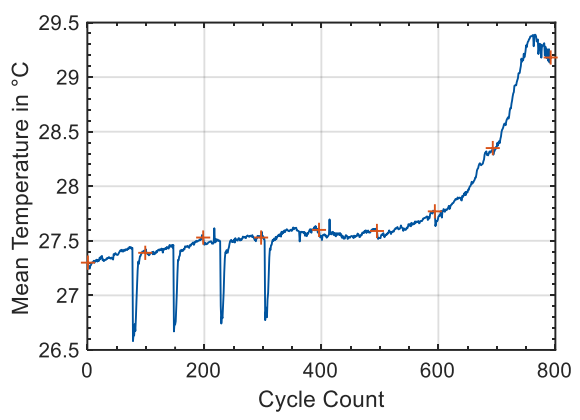

Figure 10. Mean temperature of the Samsung 35E (171). For the temperature curve, the mean temperature from the ageing cycles (SOC of 50\% and a cycle depth of $50 \%$ with $0.5 \mathrm{C}$ ) during charging was used. Therefore, this was applied over cycles and not equivalent full-cycles. The spikes interrupting the trend are caused by an opening of the temperature chamber or by other batteries aged in the same climate chamber. The red crosses mark the time of the check-ups.

\subsection{Post-Mortem Study of Samsung 35E}

Figure $11 \mathrm{~b}$ shows a CT measurement of the aged Samsung 35E (171) at a remaining capacity of $0.1 \mathrm{Ah} / \mathrm{Ah}_{\mathrm{Nom}}$. The deformation of the jelly roll is clearly visible. The deformation occurs only in the middle of the jelly roll and especially in the middle of the cell height (z-direction). For the middle five windings, deformation can be observed.

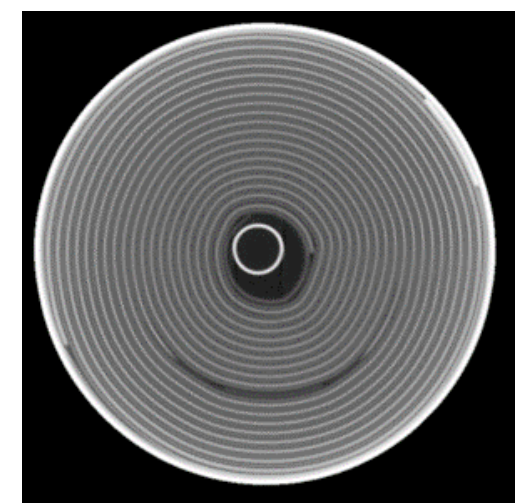

(a)

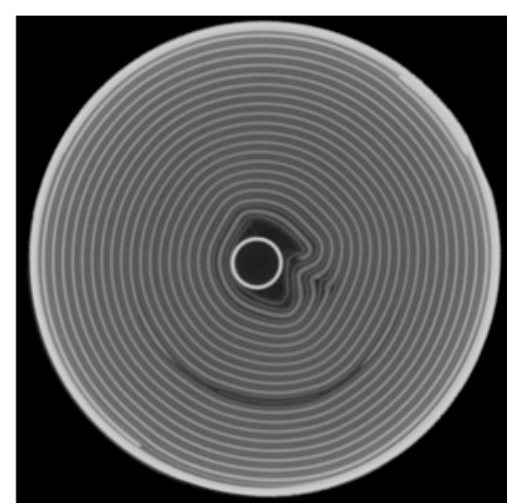

(b)

Figure 11. CT measurement of (a) an as-received Samsung 35E (347) and (b) the aged Samsung 35E (171) at a remaining capacity of $0.1 \mathrm{Ah} / \mathrm{Ah}_{\mathrm{Nom}}$. Winding deformations in the middle of the jelly roll are clearly visible.

When the aged battery was opened, clear deformations were visible in the cathode and anode, as can be seen in Figure 12a,b. In addition, a grey covering layer was formed, especially in the middle part of the jelly roll. This part started after the cathode tab. The position of the cathode tab was clearly visible on the anode due to the complete absence of the coating and the visible copper current collector (Figure 12c). 


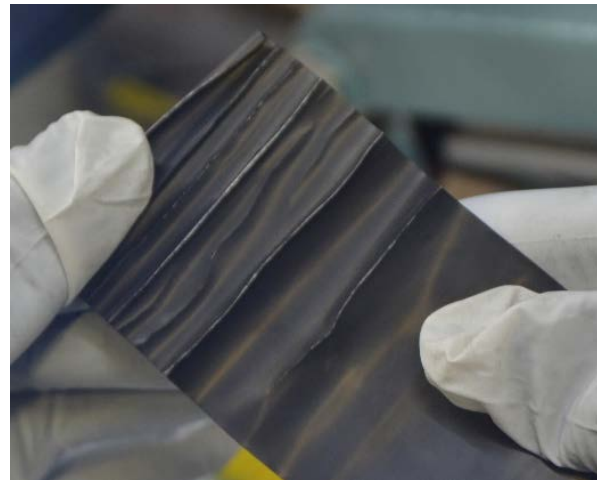

(a)

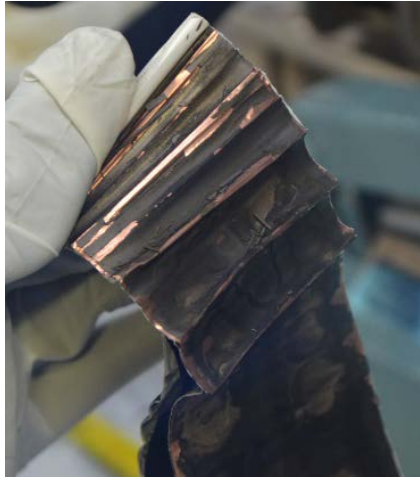

(b)

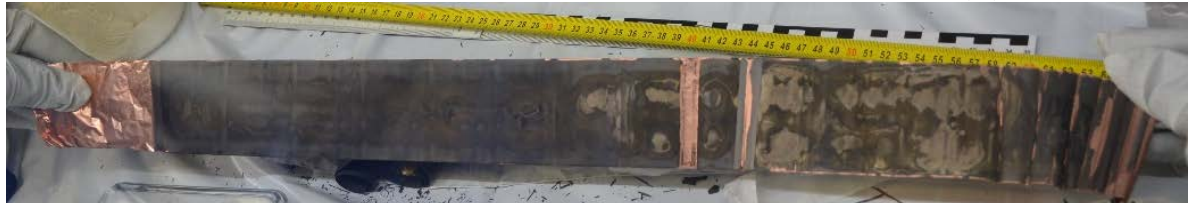

(c)

Figure 12. Pictures of electrode coatings of an aged Samsung 35E (171), (a) cathode and (b,c) anode after cell opening. Deformation and delamination are visible in each winding in the middle of the jelly roll. On the anode, a grey colored covering layer is visible.

By analyzing the electrodes with a laser microscope, it can be shown that a covering layer was formed on the anode and cathode. On the anode, the coating was not quite as pronounced in the black area (Figure 13b) as it was in the grey area (Figure 13c). However, only a few particles were still visible as in the as-received state. The particles were still visible at the cathode. Only a light covering layer was formed here (Figure 13e).

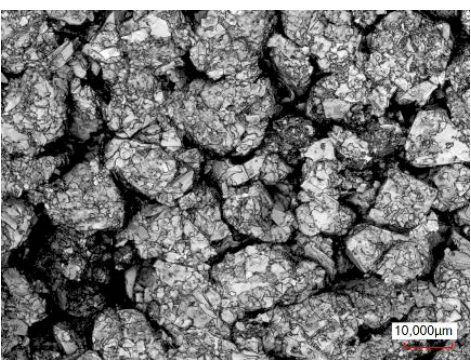

(a)

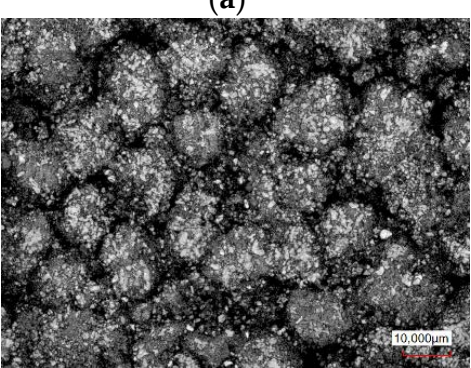

(d)

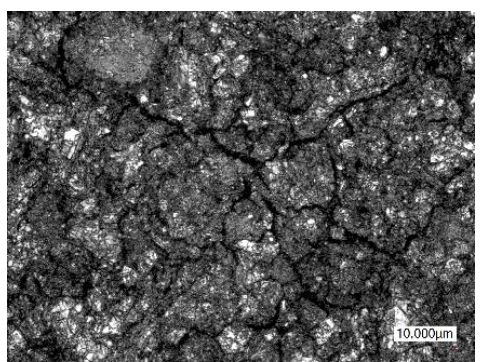

(b)

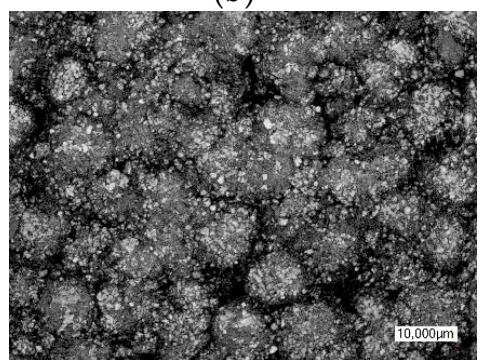

(e)

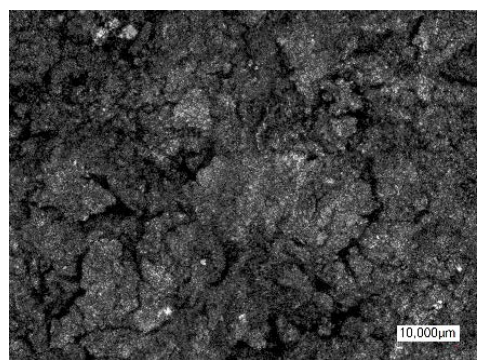

(c)

Figure 13. Laser microscope picture of the Samsung 35E, (a) anode as-received (347), (b) aged anode of a black spot of Figure 12c and (c) aged anode of a grey spot of Figure 12c (171), (d) cathode as-received (347) and (e) aged (171). 


\section{Discussion}

As could be shown in the results section, a strain gauge is a very stable and reliable measuring tool. During cycling of the Samsung 35E, the maximum permissible limit of the sensor, 50,000 $\mu \mathrm{m} / \mathrm{m}$ [30], was not exceeded until the end-of-life of the battery. Herein, a drift of $\leq 30 \mu \mathrm{m} / \mathrm{m}$ can be assumed at a cycle number of more than 100,000 equivalent full cycles. The lithium-ion battery considered here fell below the end of life capacity of $60 \%$ as given by the producer [29] already after 420 equivalent full cycles. Therefore, it can be assumed that the drift of the strain gauge was low enough for a precise time series measurement. This finding was confirmed with the investigations of the temperature influence, see Figure 2. Here, the diameter change of the Samsung 35E was measured at different temperatures for more than $20 \mathrm{~h}$ and the temperature influence was determined. It turned out that the measurement yields stable results at all temperatures. In addition, a linear temperature influence of the battery and strain gauge of $0.1 \mu \mathrm{m} /{ }^{\circ} \mathrm{C}$ could be demonstrated, which renders the temperature impact on measured results neglectable. Furthermore, it could be shown, that the expansion of the jelly roll due to temperature change had only a minor impact. Thus, the influence of temperature can be neglected. Since the lithium-ion battery did not heat up to more than $30^{\circ} \mathrm{C}$ during ageing, the temperature influence can be limited to a maximum of $0.5 \mu \mathrm{m}$ (Figure 10). This can be considered as minor compared to the measured diameter changes of more than $10 \mu \mathrm{m}$ during charge and discharge.

As shown in Figure 4 the mean diameter change of the Samsung 35E was decreasing with temperature cycle number at 0 and $40^{\circ} \mathrm{C}$. The reason for this decreasing might be a reduction of the mechanical stress within the jelly roll or a homogenization of the electrodes. This behavior requires further investigation. The decrease in the diameter change showed that the irreversible diameter change from Figure 7 is caused by effect within the battery and that the diameter of the battery was increasing over ageing.

The diameter change of the discharge process was around $10.7 \mu \mathrm{m}$ with a standard deviation of $4.4 \mu \mathrm{m}$ for an as-received lithium-ion battery. Rather large variations in battery production and ageing characteristics could be the reason for the large deviation in diameter change [31]. Further results illuminated this aspect and will be reported elsewhere.

If one considers the diameter change during discharging (Figure 5), a characteristic trend can be seen: It can be divided into three areas. A minimum at high SOC, an area with a constant gradient in medium SOC region, and a flattening slope towards the end of discharge. The impact of the electrode material of this effect is still under investigation, but relating our results with the literature suggests that the effect at low SOC might be caused by the anode [3]. Furthermore, there was little volume change in the region of medium SOC because of the stage transition of graphite (stage transition: $2 \mathrm{~L} \rightarrow 2$ [32]), which shows a plateau type of characteristic when relating to the state of charge and volume [3].

Due to the differences in diameter change that have been observed between charge and discharge, it can be assumed that intercalation and de-intercalation induce asymmetric volume changes at anode and cathode (Figure 6).

As can be seen in Figure 7, the shape of the curves remained nearly the same until a remaining capacity of $80 \%$. Then, the diameter changes receded and the characteristic shape of the curve at the beginning of charge and end of charge started to disappear. In addition, the area with a constant gradient in medium SOC range was no longer clearly visible. This might be explained by a loss of active material or active lithium which can cause less active volume overall that is used for charging and discharging or due to the fact that the electrodes have shifted to each other so that not all areas of the electrodes are used anymore. Pore clogging may lead to an increase in the reversible diameter change of the battery. In this case, the pores would no longer be available as void space for accommodating the increase in the volume of the particle during intercalation, so the diameter change of the active material was translating directly into diameter change of the cylindrical lithium-ion battery as monitored by the strain gauges.

Figure 4 shows that the irreversible diameter change stems from the battery and not from the strain gauge characteristic. Hence, the reasons for the irreversible diameter change could be an 
increase of the SEI, the non-uniform formation of a covering layer or lithium plating, or gassing [19-24]. The post-mortem results showed that a covering layer was formed over aging (Figures 12 and 13). The exact separation between SEI growths, plating or covering layer formation is unfortunately not possible. In addition, a thickening of the anode could also be observed, which fits in with the formation of the covering layer. The thickness of the anode changed from $174 \mu \mathrm{m}$ (347) to $211 \mu \mathrm{m}$ (171). The thickness of the cathode stayed constant with $156 \mu \mathrm{m}$.

The s-shaped course of the diameter change described in Figure 8 indicated two different effects that led to the diameter change variation. The s-shape course was completed from a remaining capacity of $80 \%$. Afterwards, the change in diameter increased linearly. Which effects played a role here is to be clarified further. The s-shaped course existed up to a remaining capacity of $80 \%$, which correlated well with the already shown roll over the capacity (Figure 1b).

Furthermore, the irreversible diameter change accelerated significantly at lower states-of-health (Figures 7 and 8). After check-up seven at around 420 equivalent full cycles, the lithium-ion battery suddenly lost more capacity from cycle to cycle. This was accompanied by a sudden increase in the diameter, see Figure 9. It can be assumed that due to the expansion of the anode, the pressure in the housing was increased to such an extent that the winding was deformed to reduce the pressure (Figure 11). However, the pressure increased both during the charging and discharging cycles as well as during ageing due to the ageing effects described.

At this point, it is not possible to say whether the jelly roll deformation is the reason for the sudden cell death. However, the deformation of the jelly roll could be a reason for the increasing diameter change.

Overall, there was a direct correlation between the diameter change of the lithium-ion battery and the capacity. The precise interplay between mechanistic, intercalation driven, and chemical effects deserves further investigation. The precise interplay between mechanistic, intercalation driven, and chemical effects deserves further investigation. Nevertheless, Dahn et al. [33] have shown that macroscopic deposition layers were an indicator of capacity roll-over, which was in agreement with our results.

The results can be summed up as follows: It is important to consider the volume expansion when designing and ageing lithium-ion batteries. Therefore, the strain gauges is a stable and reproducible method to analyze the volume expansion and its impact on capacity and cell death.

\section{Conclusions}

Electrochemical failure mechanisms like SEI growth, formation of a covering layer, plating, or gas formation induce mechanical stress and therefore a volume expansion. All factors increasing the probability for sudden death of the battery cell. A straightforward and reliable method for measuring the volume expansion and their influence on the state-of-health of the lithium-ion battery is the strain gauge. As we demonstrated, it yielded stable and reproducible results, when monitoring geometric variations on the micrometer scale.

The diameter change of the lithium-ion battery described a characteristic trend and is SOC and load direction-dependent. For as-received batteries of type Samsung 35E, a mean diameter change of $10.7 \mu \mathrm{m}$ during a full discharge process was measured. Different phenomena seemed to play a role in the ageing of the battery so that the change in diameter changed as a function of the ageing of the battery. Two effects can be observed over ageing using strain gauges: First, an increase of irreversible diameter change, and second, an increase of reversible diameter change. Both reversible and irreversible expansion increased with ageing. Overall, two different ageing effects led to the diameter change variation. CT measurements showed deformation of the jelly roll and post-mortem analysis showed the formation of a covering layer and the increase in the thickness of the anode.

Finally, direct correlation between the diameter change and the capacity loss of this lithium-ion battery can be identified. Therefore, the strain gauge is a tool for predicting the sudden cell death and might even serve as a diagnostic tool for the state-health, including safety aspects. 
Author Contributions: Conceptualization, L.K.W., P.D., D.U.S., and E.F.; methodology, L.K.W., G.F., and P.D.; validation, L.K.W.; formal analysis, L.K.W.; investigation, L.K.W.; resources, D.U.S. and E.F.; data curation, P.D. and L.K.W.; writing—original draft preparation, L.K.W. and E.F.; writing—review and editing, L.K.W., P.D., G.F., E.F., and D.U.S.; visualization, L.K.W. and P.D.; supervision, D.U.S. and E.F.; funding acquisition, D.U.S and E.F. All authors have read and agreed to the published version of the manuscript.

Funding: The results were generated in the research training group "mobilEM" (GRK 1856/1, 1856/2). We would like to thank the Deutsche Forschungsgemeinschaft (DFG) for funding.

Acknowledgments: This work has been done during the time as an associated member of the research training group 'mobilEM' (GRK 1856/1, 1856/2). The authors would like to thank Marcel Eckert for the setup of the test bench; Rita Graff, Martin Graff, and Niklas Kürten for the cell opening and ICP-OES measurements; and Moritz Teuber for proofreading.

Conflicts of Interest: The authors declare no conflicts of interest.

\section{References}

1. Pfrang, A.; Kersys, A.; Kriston, A.; Sauer, D.U.; Rahe, C.; Käbitz, S.; Figgemeier, E. Long-term cycling induced jelly roll deformation in commercial 18650 cells. J. Power Sources 2018, 392, 168-175. [CrossRef]

2. Waldmann, T.; Gorse, S.; Samtleben, T.; Schneider, G.; Knoblauch, V.; Wohlfahrt-Mehrens, M. A Mechanical Aging Mechanism in Lithium-Ion Batteries. J. Electrochem. Soc. 2014, 161, A1742-A1747. [CrossRef]

3. Louli, A.J.; Li, J.; Trussler, S.; Fell, C.R.; Dahn, J.R. Volume, Pressure and Thickness Evolution of Li-Ion Pouch Cells with Silicon-Composite Negative Electrodes. J. Electrochem. Soc. 2017, 164, 2689-2696. [CrossRef]

4. Cannarella, J.; Arnold, C.B. Stress evolution and capacity fade in constrained lithium-ion pouch cells. J. Power Sources 2014, 245, 745-751. [CrossRef]

5. Loveridge, M.J.; Remy, G.; Kourra, N.; Genieser, R.; Barai, A.; Lain, M.J.; Guo, Y.; Amor-Segan, M.; Williams, M.A.; Amietszajew, T.; et al. Looking deeper into the galaxy (Note 7). Batteries 2018, 4, 3. [CrossRef]

6. Vetter, J.; Novák, P.; Wagner, M.R.; Veit, C.; Möller, K.C.; Besenhard, J.O.; Winter, M.; Wohlfahrt-Mehrens, M.; Vogler, C.; Hammouche, A. Ageing mechanisms in lithium-ion batteries. J. Power Sources 2005, 147, $269-281$. [CrossRef]

7. Broussely, M.; Biensan, P.; Bonhomme, F.; Blanchard, P.; Herreyre, S.; Nechev, K.; Staniewicz, R.J. Main aging mechanisms in Li ion batteries. J. Power Sources 2005, 146, 90-96. [CrossRef]

8. Peabody, C.; Arnold, C.B. The role of mechanically induced separator creep in lithium-ion battery capacity fade. J. Power Sources 2011, 196, 8147-8153. [CrossRef]

9. Wohlfahrt-Mehrens, M.; Vogler, C.; Garche, J. Aging mechanisms of lithium cathode materials. J. Power Sources 2004, 127, 58-64. [CrossRef]

10. Zhang, N.; Tang, H. Dissecting anode swelling in commercial lithium-ion batteries. J. Power Sources 2012, 218, 52-55. [CrossRef]

11. Rieger, B.; Schlueter, S.; Erhard, S.V.; Schmalz, J.; Reinhart, G.; Jossen, A. Multi-scale investigation of thickness changes in a commercial pouch type lithium-ion battery. J. Energy Storage 2016, 6, 213-221. [CrossRef]

12. Bitzer, B.; Gruhle, A. A new method for detecting lithium plating by measuring the cell thickness. J. Power Sources 2014, 262, 297-302. [CrossRef]

13. Dolotko, O.; Senyshyn, A.; Mühlbauer, M.J.; Nikolowski, K.; Ehrenberg, H. Understanding structural changes in NMC Li-ion cells by in situ neutron diffraction. J. Power Sources 2014, 255, 197-203. [CrossRef]

14. Liu, X.H.; Wang, J.W.; Huang, S.; Fan, F.; Huang, X.; Liu, Y.; Krylyuk, S.; Yoo, J.; Dayeh, S.A.; Davydov, A.V.; et al. In situ atomic-scale imaging of electrochemical lithiation in silicon. Nat. Nanotechnol. 2012, 7, 749-756. [CrossRef] [PubMed]

15. Allart, D.; Montaru, M.; Gualous, H. Model of lithium intercalation into graphite by potentiometric analysis with equilibrium and entropy change curves of graphite electrode. J. Electrochem. Soc. 2018, 165, A380-A387. [CrossRef]

16. Dahn, J.R. Phase diagram of LixC6. Phys. Rev. B 1991, 44, 9170-9177. [CrossRef]

17. Kubota, Y.; Escao, M.C.S.; Nakanishi, H.; Kasai, H. Crystal and electronic structure of Li15Si4. J. Appl. Phys. 2007, 102, 053704. [CrossRef]

18. Li, J.; Dahn, J.R. An in situ X-ray diffraction study of the reaction of Li with crystalline Si. J. Electrochem. Soc. 2007, 154, 156-161. [CrossRef] 
19. Self, J.; Aiken, C.P.; Petibon, R.; Dahn, J.R. Survey of gas expansion in Li-Ion NMC pouch cells. J. Electrochem. Soc. 2015, 162, A796-A802. [CrossRef]

20. Kumai, K.; Miyashiro, H.; Kobayashi, Y.; Takei, K.; Ishikawa, R. Gas generation mechanism due to electrolyte decomposition in commercial lithium-ion cell. J. Power Sources 1999, 81-82, 715-719. [CrossRef]

21. Peled, E.; Menkin, S. Review-SEI: Past, present and future. J. Electrochem. Soc. 2017, 164, A1703-A1719. [CrossRef]

22. Lewerenz, M.; Warnecke, A.; Sauer, D.U. Post-mortem analysis on LiFePO4|Graphite cells describing the evolution \& composition of covering layer on anode and their impact on cell performance. J. Power Sources 2017, 369, 122-132.

23. Petzl, M.; Kasper, M.; Danzer, M.A. Lithium plating in a commercial lithium-ion battery-A low-temperature aging study. J. Power Sources 2015, 275, 799-807. [CrossRef]

24. Legrand, N.; Knosp, B.; Desprez, P.; Lapicque, F.; Raël, S. Physical characterization of the charging process of a Li-ion battery and prediction of Li plating by electrochemical modelling. J. Power Sources 2014, 245, 208-216. [CrossRef]

25. Lee, J.H.; Lee, H.M.; Ahn, S. Battery dimensional changes occurring during charge/discharge cycles-Thin rectangular lithium ion and polymer cells. J. Power Sources 2003, 119-121, 833-837. [CrossRef]

26. Grimsmann, F.; Brauchle, F.; Gerbert, T.; Gruhle, A.; Knipper, M.; Parisi, J. Hysteresis and current dependence of the thickness change of lithium-ion cells with graphite anode. J. Energy Storage 2017, 12, 132-137. [CrossRef]

27. Oh, K.Y.; Siegel, J.B.; Secondo, L.; Kim, S.U.; Samad, N.A.; Qin, J.; Anderson, D.; Garikipati, K.; Knobloch, A.; Epureanu, B.I.; et al. Rate dependence of swelling in lithium-ion cells. J. Power Sources 2014, 267, 197-202. [CrossRef]

28. Luo, J.; Dai, C.Y.; Wang, Z.; Liu, K.; Mao, W.G.; Fang, D.N.; Chen, X. In-situ measurements of mechanical and volume change of $\mathrm{LiCoO} 2$ lithium-ion batteries during repeated charge-discharge cycling by using digital image correlation. Measurement 2016, 94, 759-770. [CrossRef]

29. Specification of Product for Lithium-Ion Rechargeable Cell Model Name: INR18650-25R. Available online: https://www.orbtronic.com/content/samsung-35e-datasheet-inr18650-35e.pdf (accessed on 22 October 2019).

30. Dehnungsmessstreifen Vollendete Präzision von HBM. Available online: https://www.me-systeme.de/ produkte/dehnungsmessstreifen/catalog/s1264-DMS-Katalog-fuer-Spannungsanalyse.pdf (accessed on 22 October 2019).

31. Baumhöfer, T.; Brühl, M.; Rothgang, S.; Sauer, D.U. Production caused variation in capacity aging trend and correlation to initial cell performance. J. Power Sources 2014, 247, 332-338. [CrossRef]

32. Whittingham, M.S. Materials Challenges Facing Electrical Energy Storage. MRS Bull. 2008, 33, 411-419. [CrossRef]

33. Burns, J.C.; Kassam, A.; Sinha, N.N.; Downie, L.E.; Solnickova, L.; Way, B.M.; Dahn, J.R. Predicting and Extending the Lifetime of Li-Ion Batteries. J. Electrochem. Soc. 2013, 160, A1451-A1456. [CrossRef] 